\title{
Adaption of Learner Centric Methods in Engineering Education
}

\author{
Deepali Maste ${ }^{1}$, Dr Shrikant Kallurkar ${ }^{2}$, Dr. P.N. Nemade ${ }^{3}$ \\ ${ }^{1}$ Assistant Professor, ${ }^{2}$ Principal, ${ }^{3}$ Director \\ ${ }^{1}$ Computer Engineering Department, ${ }^{2}$ Mechanical Engineering Department,${ }^{3}$ Humanities and Social Science Department ${ }^{1}$ \\ ${ }^{123}$ Atharva College of Engineering,Malad(w),Mumbai,India \\ 1deepali.maste@gmail.com,2principal@atharvacoe.ac.in,'drpnnemade@yahoo.co.in
}

\begin{abstract}
There is a change in Face of education through new technologies and teaching and learning process. Also we expect change in education system through technological innovations in daily education activities. Learning platforms, software tools and various monitoring techniques are being developed to support the different stages of education. We face the challenge of monitoring changes in technologies and ways to deliver it to the learners. Educators should keep abreast of technological advancements that support innovations and improvements in instructional design and delivery. Atharva college of Engineering at Mumbai is committed to the mission of creating awareness among students and providing them with a unique opportunity to learn various techniques in formulating IT strategy, helping them keep abreast of the latest technologies in various avenues.
\end{abstract}

Atharva college want to yield education in new and unconventional way and through innovation so we can meet the challenges of improved efficiency, lower costs, increasing accessibility and greater success in achieving development goals.

It constantly strives and provide comprehensive technological education in a healthy learning environment, nurturing technocrat leaders for the competitive world. Our college believes in entrepreneurship which need the qualities like capacity and willingness to develop, organize and manage a business venture along with any of its risks in order to make a profit. The college has tried many innovative projects to improve teaching - learning process and develop curiosity in the mind of students. Some of the projects are Satellite Ground station, IEDC, IUCEE - SPEED, Techithon, IEEE, CSI, Paradigm of Life, etc. An opinion survey with sample of students about sense of satisfaction was carried out and presented in the paper with statistical analysis. The findings are useful to take new direction for working at our college along with providing inputs for interested colleges.

Keywords- Engineering education, innovation, atharva engineering college, teaching, learning, satellite ground station, techithon

\section{Introduction}

Assistant Professor, Computer Engineering Department, Atharva College of Engineering,Malad(w),Mumbai,India deepali.maste@gmail.com
Engineers of today are affected as technology changes every day. So traditional methods in engineering education seems no more enough to 
students for being competitive in global market. Many of the recent research specifies "what" needs to be changed in education system and very few addressed the problem of "how". What to teach and how to teach ,both are equally important. Already major steps are taken in many institutions to achieve qualitative teaching and learning. It is observed that many programs are successful in Technological innovation in engineering education but less attention is given to engineering educational innovation. Much infrastructural support is given to curriculum development and less it contributes to engineering education. To improve learning we must provide opportunities to engineering students through global educational initiatives that empower them to become leaders of engineering discovery, engagement and learning. Also we need to cultivate attitude among students like openness, willingness to participate in and learn from other cultures, etc. Skills can be developed through teamwork, self-reflexivity, leadership, critical thinking, project management, ability to cope with unfamiliarity and difference and to understand the ways in which these impact behaviors and practices and then modify social and technical practices to work effectively in multiple national contexts, etc. Many institutes work hard and employ innovative methods to make undergraduate programs less faculty-centric and more student- and worldcentric.

\section{Literature Survey}

Alan Finkel[4] explores importance of innovation in his paper that in-curriculum innovation includes increasing use of problem and project-based learning, group learning (and assessment) and thresholdconcept learning, supported by engineering education research and staff development. Having good quality work integrated learning modules within engineering degrees enhances the authenticity of the curriculum with respect to industry practice. Innovative remote laboratories and other internet-delivered course material are encouraging more educators to share best practice, and 'flip' their classrooms to improve students' active learning[4].

Eric de Graff [3] mentioned in his paper that the transition from traditional approaches in engineering education to innovative curricula based on problem based and project based learning represents a major challenge. Currently, many engineering institutions in different countries all over the world are involved in such a change process[3].
Deborah N. Huntzinger [1] state that successful integration of sustainability into engineering curricula requires a change in the approach to education. Students need not only the knowledge base to generate effective engineering solutions; they need the intellectual development and awareness to understand the impact of their decisions. Learnercentered environments are a prerequisite to the redesign of engineering education for sustainability. We examined a number of universities to determine their response to the call for inclusion of sustainability concepts into engineering curricula. A majority of the universities examined "bolted-on" various components of sustainability or student-centered learning into their existing programs[1].

R. W. King[2] concludes in his paper that the main challenge is to increase the rate of improvement and adoption of best-practice in engineering education, so that students and employers are better served. The current university-wide drivers do not, in general, provide strong incentives to academic staff to invest in much professional development of their educational skills[2].

Workman Barbara[5] discuss in his report that work based learning programmes typically start with reviewing learning and an accreditation claim, which engages the learner at the outset as the assessment relies on a compilation of their personal learning, together with evidence to support their APEL (Accreditation of Prior Experiential Learning) claim. It draws on the work practices and experience of the individual to identify learning achievement which can be recognized by the award of academic credit. This accredited learning forms the foundation of the individual's negotiated programme, building upon personal experiential learning and providing the focus for future learning. Such learning may initially come from accredited organizational training programmes or continuous professional development, or from other experiences and activities outside a traditional academic teaching environment [5].

\section{Objectives}

Our purpose for this research was to determine which attributes of technocrat leadership and competitiveness are most important for an engineer and to develop curiosity in the mind of students. We believe that a awareness about the innovations in teaching and learner centric teaching methods will help engineering institutes to focus the quality 
education of their students. So it may result that their engineering students to become more competitive.

\section{Methods: Opinion Survey Design and Implementation}

\section{Opinion Survey Design}

Here the focus is on the students' perspectives of most important things to them to be competent in the world or a good technocrat leader or to develop curiosity as a habit. We surveyed a group of students and provided them qualitative engineering methods with which they were supposed to respond by grading according to their need and interest.

The survey conducted in five parts:

1. Questionaire about innovations and knowledge addition in teaching. Here participants were asked to rate by order of importance,

2. In this participants asked to rate the importance of Project based learning.

3. Also in order to know the importance of conduction various activities to shape up overall personality, participants were asked to rate these activities if it really helps and interest them.

4. Remarks and comments collected

5 Also a series of questions given to collect demographic data that was used to analyse the results.

In this survey participants were asked to rate the attributes of quality teaching and technocrat leadership in order of importance:

1-Less helpful, 2-With Little contribution, 3Worth considering, 4-Must have, 5-Essential. Also asked the participants to give remarks and suggest if to include any other activity of their interest and growth. It is also observed that the survey may not be sufficient as can not include everything due to time and space limitation so discussions on the table held regarding overall growth of students and institutions.

\section{Q Implementation}

Here in this survey, we collected more demographic data about the participants so as to gather more information which will focus on differentiation about the opinions according to experience. This demographic data includes, Name, Age, , Class , Branch, Grade of participants. All participants were members of academia who experienced these qualitative techniques of teaching and activities.

Discussions with participants held in this regard to know that if these activities really help them to communicate effectively or will they able to evaluate properly the situations and make informed decisions in future, also if it helps them to work effectively on a team and can they relate engineering with business, social perspectives. Survey is carefully designed in such a way that that investigators doesn't know about the participants chosen in the process and attributes response from them.

\section{Results}

Questionnaire is prepared in suitable language and response is collected from approx 276 students ,who participated in it through email and on table discussion. Fig 1 shows quantitative results that age of students responded in the discussion. This demographic information is collected to know the thought process of student at particular age according to the class of student studying in. According to this graph (fig 1) approximately all students are interested to discuss and suggest about the activities which helps them to grow and improve.

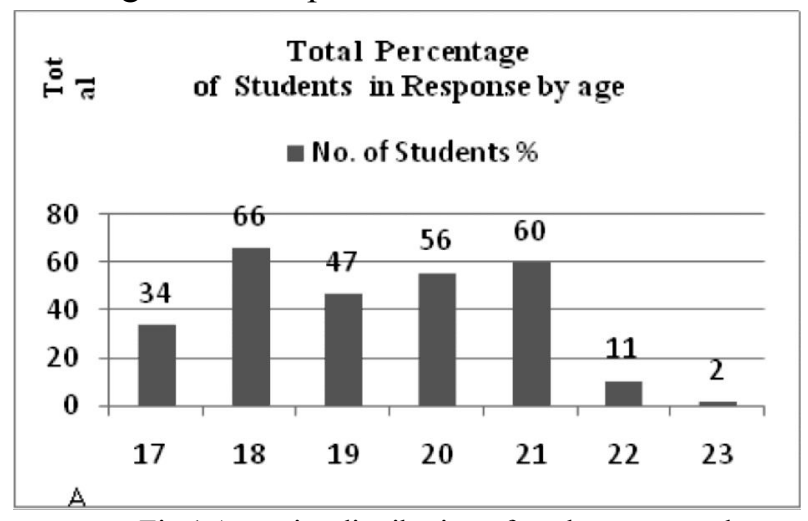

Fig 1 Age wise distribution of student surveyed.

When following set of questions as given in Table 1 is discussed with the students ,the response was amazing.

Table 1 Average of rating collected from for questions

\begin{tabular}{|l|c|}
\hline Questionnaire & $\begin{array}{c}\text { Average } \\
\text { Rating }\end{array}$ \\
\hline $\begin{array}{l}\text { Using knowledge addition/innovation } \\
\text { in the lecture? }\end{array}$ & 3.7 \\
\hline Learning by doing project helps? & 3.8 \\
\hline IEDC explore for projects/project ideas . & 3.4 \\
\hline $\begin{array}{l}\text { Technical activities such as Techithon helps in } \\
\text { knowledge building, team work and social } \\
\text { learning. }\end{array}$ & 3.9 \\
\hline
\end{tabular}




\begin{tabular}{|l|c|}
\hline Questionnaire & $\begin{array}{c}\text { Average } \\
\text { Rating }\end{array}$ \\
\hline $\begin{array}{l}\text { Updates with global trends and technologies } \\
\text { through IEEE 360 and CSI }\end{array}$ & 3.9 \\
\hline $\begin{array}{l}\text { Social skills and Personality development } \\
\text { through Paradigm of Life }\end{array}$ & 3.5 \\
\hline $\begin{array}{l}\text { Regular updating at MOODLE helps to keep } \\
\text { updated withstudy/practical/exam/placement/ } \\
\text { resources }\end{array}$ & 3.9 \\
\hline Creativity boost through E-Week & 3.5 \\
\hline $\begin{array}{l}\text { Organizing Festivals and annual functions in the } \\
\text { college }\end{array}$ & 4.2 \\
\hline Knowledge Addition through Virtual & 3.9 \\
\hline
\end{tabular}

Students seems more interested in teamwork activities like technical festivals and social gathering. Also it is very satisfying that Knowledge addition and Innovation trend we started in the college helps them a lot and they feel updated with the latest technology. All data at one place and regular updating it by faculty members and providing helpful resources keep them in the flow and connected in the process. Also we got a good response to newly started venture of IEDC explore which gives students a platform to represent their project and get sponsorship for it . As we are proud of one of the achievements as Satellite Ground Station is one of the projects done by Electronics students is recognized and funded by IEDC and proved commercially successful too.

In order to clearly see which questions were ranked as most important, the questions were graphed in order of importance in fig 2 .

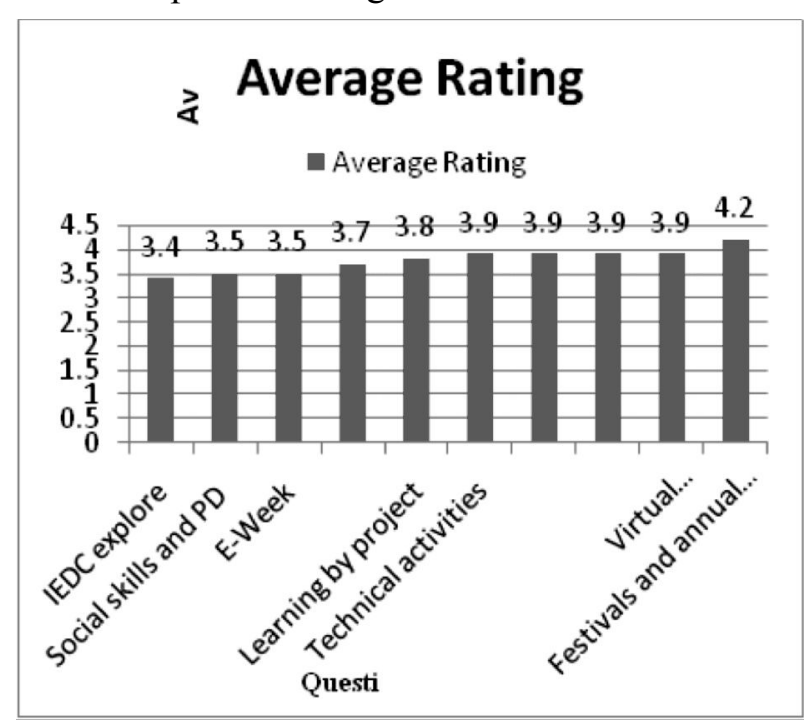

Fig 2 This graph shows average of response to questions

When asked to provide additional remarks to describe their need to improve technically and socially, the students brought up some interesting issues. Some students stressed the need for increased global awareness while some feel that time management is also crucial in the development. In this process we also got some neutral responses to some of the questions as students were still confused about their aim and activities they want to involve in so we are awaiting their response as we improvise our system to fulfill every one's valid demands.

Some students also feel that they want to feel connected to the college during holidays also through online centralized system. In the discussion many students stressed on providing them more recent technological platform to work on the projects.

Internship and industrial training is a area in which most of the students are interested in ,as they insisted in the discussion to provide it to every one of them.

\section{Discussion}

As every creative idea does not give guarantee of success. Many times we had to face implementation failure due to technical drawbacks and improper planning methods. But again by putting consistent and systematic effort we were able to achieve success. Here we are sure that with the ideas, implementation, feedback and change cycle, we will be able to reach the goal of quality education.

\section{Conclusion}

From these results, it can be determined that the top five most important attributes of development of student and institutions, as indicated by our survey are:

1. Team work building and social learning plays vital role in the student's development and make them interested always. So arranging technical activities in systematic manner may help them in future.

2. Student wants to feel connected always. Centralized data (MOODLE) and regular updating to it keeps them interested and helps them to achieve career goals.

3. Global trends and technology, in which students are always interested to know the world so at least virtual seminar/class/lab we can provide.

4. When you do you learn most, is the key to success so giving importance to project work and providing platform is much better way to get them learn the technology. 
5. Innovative ideas to teach subjects is a new way to go so we follow it through role play, game play, quiz, debate etc.

In concluding this, we believe that engineering education field realized the need for learner centric methods. Here we face the challenges which are common between various engineering colleges of metropolitan city so our survey may help them to adopt new dimension to leaner centric methods in engineering education.

\section{Limitations}

Though our survey includes the problem area faced by engineering student and their response to various learner centric technical activities initiated at our college, engineering students from other colleges of city except metropolitan city may have different need and expectation in engineering education so our survey might less useful to them .

\section{Acknowledgement}

The authors would like to thank Executive President of Atharva college of Engineering, Hon. Shri Sunil Rane for support and encouragement all the time. Also we thank all of the participants as students, faculty members and other authorities in our survey for their valuable time which help us reach our goal. Also we would like to thank all HODs of our college for providing us valuable information through discussions. We would like to thank specially to IEDC coordinator of our college Dr. Anupama Deshpande. Also appreciating the help provided by Prof Mahendra Patil and Jayashri Jha for the survey.

\section{References}

[1] Deborahn,Huntzinger,Margot J. Hutchins,John S. Gierke and John W Sutherland, Enabling Sustainable Thinking in Undergraduate Engineering Education ," 0949 149X/91,Temptus publication,2007

[2] R. W. King ,National Processes to Support Continuous Improvement in Engineering Education in Australia, 40th annual Conference on Quality Assurance and Accreditation, Thessaloniki, Greece,Sept 2012

[3] Erric Graaff,Annette Kolomos,Management of Change,ISBN 90-87-013-9, Sense publishers 2007

[4] Alan Finkel, Innovative Approaches to Engineering Education, CAETS 2013 Budapest - June 27, 2013

[5] Barbara Workman,Teaching, Learning and Assessing Work Based Learning, ISBN 9781904750192 Middlesex University Press, London,2009 